\title{
The Relation of the US Dollar with Oil Prices, Gold Prices, and the US Stock Market
}

\author{
Samih Antoine Azar ${ }^{1}$ \\ ${ }^{1}$ Faculty of Business Administration \& Economics, Haigazian University, Beirut, Lebanon \\ Correspondence: Samih Antoine Azar, Professor, Faculty of Business Administration \& Economics, Haigazian \\ University, Mexique Street, Kantari, Beirut, Lebanon. Tel: 961-1-349-230. E-mail: samih.azar@haigazian.edu.lb
}

Received: February 9, 2015

Accepted: February 24, $2015 \quad$ Online Published: March 2, 2015

doi:10.5430/rwe.v6n1p159

URL: http://dx.doi.org/10.5430/rwe.v6n1p159

\begin{abstract}
The purpose of this paper is to study the relation of US stocks, gold, and oil with the US dollar foreign exchange rate. First it is demonstrated that the law of one price holds for US stocks, gold, and oil. This law specifies that a $1 \%$ appreciation of the US dollar leads to a $1 \%$ fall in the price of stocks, gold, and oil. This is true for the simple reason that stocks, gold and oil are denominated in US dollars. Next intrinsic returns are calculated. Intrinsic returns are defined as those asset returns that treat the US dollar unchanged. Although raw returns are marginally negatively correlated with the US dollar, intrinsic returns and the US dollar are essentially independent. Nevertheless the paper uncovers a calendar break in September 2002. Before this date raw and intrinsic returns of US stocks are positively correlated with the US dollar, while they are negatively correlated afterwards. The implications for portfolio analysis are clear-cut: investors should hold a portfolio that is long in equity, gold and oil, although oil has on average a zero return and suffers from excess volatility. It may seem that foreigners benefit additionally from a stronger dollar. However the US dollar has itself a zero average return.
\end{abstract}

Keywords: US dollar, US stocks, oil prices, gold prices, law of one price, intrinsic returns, average returns, portfolio analysis

\section{Introduction}

The relation between the price of the US dollar on one hand and the prices of other assets like gold, oil, and stocks on the other hand is inherently interesting for many reasons. It enables one to answer some specific questions. Are the four asset markets connected? What is the sign and magnitude of this connection? Do these assets act as diversifiers? Is it worthwhile to include all four assets in the same portfolio? Is the dollar the exogenous variable? What is the effect of the dollar on these three assets? Can one apply the law of one price for these assets relative to the dollar? What are the intrinsic returns on gold, oil, and stocks after adjustment for the dollar fluctuations? Is the relation a long run or a short run one? Should one use cointegration analysis although this technique violates market efficiency in its error-correction representation? Are the relations stable across regimes and over time? All these questions deserve consideration. Unfortunately the literature on the subject does not cover these four assets together and simultaneously. Some studies cover the relation between gold, oil, and foreign exchange rates (Hammoudeh et al., 2008; Malliaris and Malliaris, 2013). Others include stocks in the analysis and its relation to the dollar but fail to consider gold and oil (Kollias et al., 2012; Inci and Lee, 2013; Azar, 2013a, 2013b, 2014). Some omit the dollar and the stock market (Ivanov 2011; Lee et al., 2012; Beckmann and Czudaj, 2013). Still others dwell uniquely on gold and the dollar (Zagaglia and Marzo, 2013), or uniquely on the dollar and oil (Bonitsis and Rezvani, 2010), or uniquely on oil and stocks (Abyankar, et al., 2013), or uniquely on stocks and gold (Baur and Lucey, 2010; Miyazaki and Hamori, 2013). This paper has the advantage of covering the four assets simultaneously.

The approach in this paper is totally distinguishable from the literature. First, there is no attempt to estimate long run relations using cointegration or short run relations using error-correction models, or test for Granger causality, or doing a VAR methodology, or a non-linear VAR and a non-linear VECM. All variables are defined by their stationary statistical processes, i.e. by the first difference of their natural logs. With monthly data these are approximately percentage returns. Second, in most of the analysis the US dollar is the exogenous asset. This is evident since all the other three assets are denominated in US dollars. Third the law of one price, applied to the three assets relative to the dollar, is tested. See on this Akram (2009), Pukthuanthong and Roll (2011) and Beckmann and 
Czudaj (2013). Fourth, having established the law of one price, the intrinsic returns on the three assets relative to the dollar are derived. These intrinsic returns are the returns that one can obtain on each asset if the dollar exchange rate were completely stable. The intrinsic returns on gold and on stocks are statistically significantly positive, while the oil intrinsic returns are statistically insignificant, i.e. they have a zero average return. Preliminary evidence shows that the dollar fluctuations are independent of these intrinsic returns. However further scrutiny reveals that there is a calendar break in the relation. It is found that the dollar returns and the intrinsic returns on stocks are positively related before 2002 but negatively related after 2002. In other terms an appreciation of the dollar raises stock prices before 2002, but lowers stock prices afterwards. In turn gold prices affect the dollar before 2002 but fail to influence the dollar after 2002. Finally the intrinsic returns on oil are independent of the dollar returns.

In what concerns raw data of returns, the US dollar is negatively related with the returns on gold, oil, and stocks. In the three cases the relation is statistically significant. There is only one differential impact of stocks before September 2002. Before this date the impact is positive: an increase in stock prices is associated with a strong US dollar. After 2002 an increase in stock prices is accompanied by a fall in the US dollar. Remarkably, the negative effect and the positive effect are statistically equal in absolute values. There are clear-cut theoretical reasons for a negative relation. A depreciation of the US dollar makes imports more expensive and exports cheaper. Consequently imports decrease and exports increase. Aggregate output becomes higher, and cash flows for importing firms soar, increasing equity prices. Another mechanism works in opposition. Higher equity prices raises wealth. The demand for money becomes more intense, putting pressure on interest rates that go up. Higher interest rates in turn lead to capital inflows and dollar appreciation. It seems that this second transmission channel predominated before 2002, while the first channel has more explanatory power for the recent period, after 2002.

For portfolio purposes it seems worthwhile to a US investor to long the equity index, oil and gold, because of the low, or marginally negative, correlation coefficients with the US dollar. This is true because portfolio variances would be low with low correlation coefficients. But the other side of the coin is that the joint portfolio returns may be also low. The same strategy works for foreigners who get the extra return of an appreciating dollar. One caveat is that while intrinsic oil returns have low correlation coefficients with the dollar, oil does not add a marginal return. Oil serves only to reduce portfolio risk without bringing additional reward. Similarly for the foreigner a strengthening of the US dollar brings economic benefits by enhancing capital gains. However the average return on the dollar is insignificantly different from zero.

The paper is organized as follows. The next section is the empirical part. It is divided into 8 parts, each pertaining to a statistical table. The first three tables dwell on the law of one price. The fourth table uncovers the relation between gold, oil, and US stocks with the US dollar. The fifth table studies the relation between intrinsic returns and the US dollar. Since there is a calendar break the sixth table defines a dummy variable for the break and includes it interactively with the other three intrinsic asset returns. Table 7 calculates short run and long run raw and intrinsic returns. Finally the last part dwells on some limitations of the research of this paper.

\section{Empirical Results}

All the data is retrieved from the web site of the Federal Reserve Bank of Saint Louis: gold prices, oil prices, the trade-weighted US dollar, and the stock market index. The common sample is monthly and starts in January 1985 and ends in November 2014 and this makes 359 observations per variable. All variables are converted to log returns by taking the first difference of the natural logarithm.

\subsection{The Law of One Price for Gold}

Tables 1, 2, and 3 present tests for the law of one price. In this context this law stipulates that a $1 \%$ appreciation in the US dollar trade-weighted foreign exchange rate leads to a $1 \%$ decline in the price of gold (Table 1), in the price of oil (Table 2), and in the stock market price (Table 3). In Table 1 the log returns of gold are regressed over the log returns of the dollar, the log returns of US stocks, the log returns of oil, and the lagged log returns of the dependent variable. The reason for including the lagged dependent variable is due to autocorrelation induced by averaging (Working, 1960), and not due to market inefficiency. The coefficient on the log returns of US stocks is not statistically significantly different from zero as it carries a t-statistic of 1.683747. Omitting this variable does not affect materially the other coefficients and their statistical significance. Unfortunately the Akaike information criterion is higher, which denotes that one should not omit the said variable. The effect of changes in oil prices on the gold $\log$ returns is positive, varies between 0.057964 and 0.058327 , and has t-statistics ranging between 2.244084 and 2.263912. Considering the second, restricted regression, the coefficient on the log returns of the US dollar is -1.033503 , has a t-statistic of 5.473934, and is insignificantly different from -1 with a t-statistic of -0.177450 . This coefficient is the contemporaneous short run effect. This establishes the law of one price for the short run. The 
delayed and long run effect is obtained by dividing this coefficient by one minus the coefficient on the lagged dependent variable. This effect is -0.858808 , and is insignificantly different from -1 with a t-statistic of 0.926319 . This establishes the law of one price for the long run. Hence the law of one price is established for both the short and long runs. This last regression has a Durbin-Watson statistic of 2.008708 , denoting absence of first-order serial correlation. Since the data is monthly higher-order serial correlation should be checked for lags that are a multiple of 3. Higher-order serial correlation, for lags $6,12,18$, and 24, is rejected by the p-values on the Ljung-Box Q-statistics, p-values which are all higher than $20 \%$ failing to reject the null of no higher-order serial correlation. Unfortunately the Ljung-Box Q-statistics on the squared residuals obtain low actual p-values: 0.001 for 6 lags, 0.011 for 12 lags, 0.009 for 18 lags, and 0.001 for 24 lags. This is evidence of conditional heteroscedasticity or ARCH effects. In fact the ARCH test for 6 lags has an actual p-value of 0.0045, rejecting the null of homoscedasticity. The Jarque-Bera test rejects the null of a normal distribution for the residuals with a p-value of 0.001073 . However since the sample size is rather big one can still undertake hypothesis testing by invoking the central limit theorem.

Table 1. Evidence for the law of one price for gold. The dependent variable is $\Delta[\log ($ gold $)]$

\begin{tabular}{|c|c|c|c|}
\hline & Ordinary least squares & Ordinary least squares & $\operatorname{GARCH}(1,1)$ \\
\hline Constant & $\begin{array}{c}0.006643 \\
(2.858275)\end{array}$ & $\begin{array}{c}0.005739 \\
(2.531424)\end{array}$ & $\begin{array}{c}0.004798 \\
(2.258795)\end{array}$ \\
\hline$\Delta[\log ($ dollar $)]$ & $\begin{array}{l}-1.127289 \\
(5.740251)\end{array}$ & $\begin{array}{l}-1.033503 \\
(5.473934)\end{array}$ & $\begin{array}{l}-0.878955 \\
(4.687335)\end{array}$ \\
\hline$\Delta[\log ($ stocks $)]$ & $\begin{array}{l}-0.107339 \\
(1.683747)\end{array}$ & & \\
\hline$\Delta[\log ($ oil $)]$ & $\begin{array}{c}0.058327 \\
(2.263912)\end{array}$ & $\begin{array}{c}0.057964 \\
(2.244084)\end{array}$ & $\begin{array}{c}0.066977 \\
(2.818920)\end{array}$ \\
\hline \multirow[t]{2}{*}{$\Delta[\log (\operatorname{gold}(-1))]$} & $\begin{array}{l}-0.220240 \\
(4.226486)\end{array}$ & $\begin{array}{l}-0.203417 \\
(3.967200)\end{array}$ & $\begin{array}{l}-0.179833 \\
(3.088024)\end{array}$ \\
\hline & & & $\begin{array}{c}\text { Conditional variance } \\
\text { equation }\end{array}$ \\
\hline Constant & & & $\begin{array}{c}0.000174 \\
(1.657846)\end{array}$ \\
\hline $\mathrm{ARCH}(1)$ & & & $\begin{array}{c}0.111109 \\
(2.219921)\end{array}$ \\
\hline GARCH(1) & & & $\begin{array}{c}0.789142 \\
(8.598457)\end{array}$ \\
\hline Adjusted R-Square & 0.119827 & 0.11527 & 0.11315 \\
\hline Akaike information criterion & -3.476389 & -3.473984 & -3.515202 \\
\hline Durbin-Watson statistic & 2.008353 & 2.008708 & 2.043384 \\
\hline $\mathrm{Q}(6)$ & & 0.301 & 0.701 \\
\hline $\mathrm{Q}(12)$ & & 0.179 & 0.467 \\
\hline $\mathrm{Q}(18)$ & & 0.362 & 0.594 \\
\hline $\mathrm{Q}(24)$ & & 0.346 & 0.741 \\
\hline$Q^{2}(6)$ & & 0.001 & 0.479 \\
\hline $\mathrm{Q}^{2}(12)$ & & 0.011 & 0.710 \\
\hline$Q^{2}(18)$ & & 0.009 & 0.918 \\
\hline$Q^{2}(24)$ & & 0.001 & 0.510 \\
\hline Jarque-Bera & & 0.001073 & 0.004293 \\
\hline
\end{tabular}

Notes: The variable 'gold' is for the price of gold. The variable 'dollar' is for the trade-weighted US dollar. The variable 'oil' is for the price of oil. The variable 'stocks' is for the US stock market index. $\Delta$ is for the first-difference operator. Log stands for the natural logarithm. Absolute t-statistics are in parentheses. $Q(k)$ is the actual p-value of the Ljung-Box Q-statistic for lag length $\mathrm{k}$, on the residuals for column 3, and on the standardized residuals for column 4. Q(k) tests for serial correlation. The null is for no serial correlation. A low p-value is rejection of the null. $\mathrm{Q}^{2}(\mathrm{k})$ is the actual p-value of the Ljung-Box Q-statistic for lag length $\mathrm{k}$, on the residuals squared for column 3, and 
on the standardized residuals squared for column $4 . \mathrm{Q}^{2}(\mathrm{k})$ tests for conditional heteroscedasticity. The null is for homoscedasticity or constant variance. A low p-value is rejection of the null. Jarque-Bera is the actual p-value of the Jarque-Bera normality test on the residuals for column 3 and on the standardized residuals for column 4. A low p-value is rejection of the null. In the $\operatorname{GARCH}(1,1)$ model Bollerslev-Wooldridge robust standard errors and covariance are applied (Bollerslev and Wooldridge, 1992).

Since there is evidence of $\mathrm{ARCH}$ effects, either from the ARCH test, or from the Ljung-Box Q-statistics, a GARCH $(1,1)$ model is estimated with the same variables as in the restricted regression (see column 4 in Table 1). Oil has a slightly higher effect than before with a coefficient of 0.066977 that has a more significant t-statistic of 2.818920. The short run impact of the dollar variable is -0.878955 , has an absolute t-statistic of 4.687335 , and is insignificantly different from -1 with a t-statistic of 0.645516 . The long run impact, calculated as before, is further away from -1 at -0.744982 but is still insignificantly different from -1 with a t-statistic of 1.684947 that has a two-tailed p-value of 0.0920 . Among the three regressions tabulated in Table 1 the $\operatorname{GARCH}(1,1)$ model is the superior with the lowest Akaike information criterion of -3.515202. Moreover all econometric diagnostics such as serial correlation of the residuals and heteroscedasticity are rejected making the $\mathrm{GARCH}(1,1)$ the most appropriate. A note of caution is due however because the standardized residuals are still non-normally distributed.

Table 2. Evidence for the law of one price for oil. The dependent variable is $\Delta[\log ($ oil $)]$

\begin{tabular}{|c|c|c|c|}
\hline & Ordinary least squares & Ordinary least squares & $\operatorname{GARCH}(1,1)$ \\
\hline \multirow[t]{2}{*}{ Constant } & 0.002929 & 0.003447 & 0.003287 \\
\hline & $(0.632636)$ & $(0.763362)$ & $(0.961186)$ \\
\hline \multirow[t]{2}{*}{$\Delta[\log ($ dollar $)]$} & -1.439638 & -1.493757 & -1.418843 \\
\hline & (3.747804) & $(4.044570)$ & $(5.140136)$ \\
\hline \multirow[t]{2}{*}{$\Delta[\log ($ stocks $)]$} & 0.065392 & & \\
\hline & $(0.519024)$ & & \\
\hline \multirow[t]{2}{*}{$\Delta[\log ($ gold $)]$} & 0.217227 & 0.214742 & \\
\hline & $(2.110232)$ & $(2.090504)$ & \\
\hline \multirow[t]{3}{*}{$\Delta[\log (\operatorname{oil}(-1))]$} & 0.229432 & 0.227020 & 0.183620 \\
\hline & $(4.562164)$ & $(4.538288)$ & $(2.792316)$ \\
\hline & & & $\begin{array}{c}\text { Conditional variance } \\
\text { equation }\end{array}$ \\
\hline \multirow[t]{2}{*}{ Constant } & & & 0.000700 \\
\hline & & & $(2.453563)$ \\
\hline \multirow[t]{2}{*}{$\mathrm{ARCH}(1)$} & & & 0.356249 \\
\hline & & & $(2.753700)$ \\
\hline \multirow[t]{2}{*}{ GARCH(1) } & & & 0.592913 \\
\hline & & & $(5.428318)$ \\
\hline Adjusted R-Square & 0.12437 & 0.12618 & 0.113808 \\
\hline Akaike information criterion & -2.093374 & -2.098198 & -2.236384 \\
\hline Durbin-Watson statistic & 2.011050 & 2.006734 & 1.902118 \\
\hline $\mathrm{Q}(6)$ & & 0.135 & 0.168 \\
\hline $\mathrm{Q}(12)$ & & 0.037 & 0.061 \\
\hline $\mathrm{Q}(18)$ & & 0.020 & 0.011 \\
\hline $\mathrm{Q}(24)$ & & 0.015 & 0.010 \\
\hline$Q^{2}(6)$ & & 0.000 & 0.883 \\
\hline$Q^{2}(12)$ & & 0.000 & 0.544 \\
\hline $\mathrm{Q}^{2}(18)$ & & 0.002 & 0.772 \\
\hline $\mathrm{Q}^{2}(24)$ & & 0.008 & 0.120 \\
\hline Jarque-Bera & & 0.000000 & 0.002483 \\
\hline
\end{tabular}

Notes: Absolute t-statistics are in parentheses. $\mathrm{Q}(\mathrm{k})$ is the actual p-value of the Ljung-Box Q-statistic for lag length $\mathrm{k}$, on the residuals for columns 2 and 3, and on the standardized residuals for column 4 . Q(k) tests for serial correlation. 
The null is for no serial correlation. A low p-value is rejection of the null. $\mathrm{Q}^{2}(\mathrm{k})$ is the actual $\mathrm{p}$-value of the Ljung-Box Q-statistic for lag length $\mathrm{k}$, on the residuals squared for columns 2 and 3, and on the standardized residuals squared for column $4 . \mathrm{Q}^{2}(\mathrm{k})$ tests for conditional heteroscedasticity. The null is for homoscedasticity or constant variance. A low p-value is rejection of the null. Jarque-Bera is the actual p-value of the Jarque-Bera normality test on the residuals for columns 2 and 3 , and on the standardized residuals for column 4. A low p-value is rejection of the null. In the $\operatorname{GARCH}(1,1)$ model Bollerslev-Wooldridge robust standard errors and covariance are applied (Bollerslev and Wooldridge, 1992).

\subsection{The Law of One Price for Oil}

In Table 2 the log returns of oil are regressed over the log returns of the dollar, the log returns of US stocks, the log returns of gold, and the lagged log returns of the dependent variable. The coefficient on the log returns of US stocks is not statistically significantly different from zero as it carries a t-statistic of 0.519024 . This is comparable to the results with the regression on gold log returns in Table 1. Omitting the stocks variable does not affect materially the other coefficients and their statistical significance. The Akaike information criterion is lower in the restricted regression, which denotes that one is justified to omit the said variable. The effect of changes in gold prices on the oil $\log$ returns is positive, varies between 0.217227 and 0.214742 , and has t-statistics ranging between 2.090504 and 2.110232. Considering the restricted regression, the coefficient on the log returns of the US dollar is -1.493757 , not far away from the coefficient of -1.439638 in the unrestricted regression. This coefficient has a t-statistic of 4.044570, and is insignificantly different from -1 with a t-statistic of -1.336922 . This coefficient is the contemporaneous short run effect, and establishes the law of one price for the short run. The delayed and long run effect is obtained by dividing this coefficient by one minus the coefficient on the lagged dependent variable. This effect is -1.932467 , and is marginally insignificantly different from -1 with a t-statistic of -1.949774 . This establishes marginally the law of one price for the long run as the two-tailed p-value is close to $5 \%$ and is equal to 0.0520 . Hence the law of one price is established for the short run and marginally for the long run. This last regression has a Durbin-Watson statistic of 2.006734, denoting absence of first-order serial correlation. Since the data is monthly higher-order serial correlation should be checked for lags that are a multiple of 3. Higher-order serial correlation, for lags 12, 18, and 24, is not rejected by the p-values on the Ljung-Box Q-statistics, $p$-values which are all lower than $4 \%$ rejecting the null of no higher-order serial correlation. Only the statistic for a lag length of 6 has a p-value higher than $10 \%(0.135)$. The Ljung-Box Q-statistics on the squared residuals obtain low actual p-values: 0.000 for 6 lags, 0.000 for 12 lags, 0.002 for 18 lags, and 0.008 for 24 lags. This is evidence of conditional heteroscedasticity or ARCH effects. In fact the ARCH test for 6 lags has an actual p-value of 0.0008 , rejecting the null of homoscedasticity. The Jarque-Bera test rejects the null of a normal distribution for the residuals with a p-value that is less than 0.000001 . However since the sample size is rather big one can still undertake hypothesis testing by invoking the central limit theorem.

Since there is evidence of ARCH effects, either from the ARCH test, or from the Ljung-Box Q-statistics, a GARCH(1,1) model is estimated with the same variables as in the restricted regression (see column 4 in Table 2). Gold and stocks are omitted from the model. The p-value that the two coefficients on these two variables are jointly zero is 0.1698 . The short run impact of the dollar variable is -1.418843 , not far away from the Ordinary Least Squares results, has an absolute t-statistic of 5.140136, and is insignificantly different from -1 with an absolute t-statistic of 1.517369. The long run impact, calculated as before, is further away from -1 at -1.737969 but is significantly different from -1 with an absolute t-statistic of 2.430459 , that has a two-tailed p-value of 0.0151 . Hence, although the law of one price is established for the short run, it fails to hold in the long run. In the long run there is overshooting of oil prices relative to the US dollar. Among the three regressions tabulated in Table 2 the GARCH(1,1) model is the superior with the lowest Akaike information criterion of -2.236384 . The econometric diagnostics on the standardized residuals show that serial correlation did not disappear, especially at lag lengths of 18 and 24. A note of caution is due however because the residuals are still non-normally distributed.

\subsection{The Law of One Price for US Stocks}

In Table 3 the log returns of the US stock index are regressed over the log returns of the dollar, the log returns of oil, the log returns of gold, and the lagged log returns of the dependent variable. The two coefficients on the log returns of the oil price and the gold price are not statistically significantly different from zero as they carry t-statistics of 0.476663 and 0.818048 respectively. This is comparable to the results with the regression on gold $\log$ returns and oil returns in Tables 1and 2. Hence there is strong evidence that US stocks do not have a significant relation with gold and oil prices. Omitting these last two variables does not affect materially the other coefficients and their statistical significance. However, the Akaike information criterion is surprisingly higher in the restricted regression, which denotes that one is not justified to omit the said two variables. In the restricted regression, the coefficient on the log 
returns of the US dollar is -0.702198 , not far away from the coefficient of -0.749453 in the unrestricted regression. This coefficient has an absolute t-statistic of 2.876853 , and is statistically insignificantly different from -1 with a t-statistic of 1.220074. This coefficient is the contemporaneous short run effect, and establishes the law of one price for the short run. The delayed and long run effect is obtained by dividing this coefficient by one minus the coefficient on the lagged dependent variable. This effect is -0.959514 , and is statistically insignificantly different from -1 with a $\mathrm{t}$-statistic of 0.117143 . This establishes the law of one price for the long run. Hence the law of one price is established for the short run and for the long run. This last regression has a Durbin-Watson statistic of 1.923887, denoting absence of first-order serial correlation. Since the data is monthly higher-order serial correlation should be checked for lags that are a multiple of 3 . Higher-order serial correlation, for lags $6,12,18$, and 24, is rejected by the p-values on the Ljung-Box Q-statistics, p-values which are all higher than $5 \%$ failing to reject the null of no higher-order serial correlation. The Ljung-Box Q-statistics on the squared residuals obtain the following actual p-values: 0.003 for 6 lags, 0.018 for 12 lags, 0.120 for 18 lags, and 0.159 for 24 lags. This is weak evidence of conditional heteroscedasticity or ARCH effects. In contrast the ARCH test for 12 lags has an actual p-value of 0.1099 , failing to reject the null of homoscedasticity. The Jarque-Bera test rejects the null of a normal distribution for the residuals with a p-value that is less than 0.000001 . However since the sample size is rather big one can still undertake hypothesis testing by invoking the central limit theorem. Since there is little evidence of ARCH effects, either from the ARCH test, or from the Ljung-Box Q-statistics on the squared residuals, a GARCH model is not estimated.

Table 3. Evidence for the law of one price for stocks. The dependent variable is $\Delta[\log$ (stocks) $]$

\begin{tabular}{ccc}
\hline & Ordinary least squares & Ordinary least squares \\
\hline Constant & 0.006015 & 0.005845 \\
& $(3.227067)$ & $(3.477030)$ \\
$\Delta[\log ($ dollar $)]$ & -0.749453 & -0.702198 \\
& $(4.904081)$ & $(2.876853)$ \\
$\Delta[\log ($ oil $)]$ & -0.010075 & \\
$\Delta[\log ($ gold $)]$ & $(0.476663)$ & \\
$\Delta[\log ($ stocks(-1)) & -0.034396 & 0.268173 \\
& $(0.818048)$ & $(6.075689)$ \\
Adjusted R-Square & 0.284368 & 0.130820 \\
Akaike information criterion & $(5.744919)$ & -3.843879 \\
& & \\
Durbin-Watson statistic & 0.136206 & 1.923887 \\
$\mathrm{Q}^{(6)}$ & -3.893928 & \\
$\mathrm{Q}(12)$ & 1.918316 & 0.071 \\
$\mathrm{Q}(18)$ & & 0.114 \\
$\mathrm{Q}(24)$ & & 0.246 \\
$\mathrm{Q}^{2}(6)$ & & 0.459 \\
$\mathrm{Q}^{2}(12)$ & & 0.003 \\
$\mathrm{Q}^{2}(18)$ & & 0.018 \\
$\mathrm{Q}^{2}(24)$ & & 0.120 \\
Jarque-Bera & & 0.159 \\
\hline
\end{tabular}

Notes: Absolute t-statistics are in parentheses. Q(k) is the actual p-value of the Ljung-Box Q-statistic for lag length $\mathrm{k}$ on the residuals. $\mathrm{Q}(\mathrm{k})$ tests for serial correlation. The null is for no serial correlation. A low p-value is rejection of the null. $\mathrm{Q}^{2}(\mathrm{k})$ is the actual p-value of the Ljung-Box Q-statistic for lag length $\mathrm{k}$ on the residuals squared. The null is for homoscedasticity or constant variance. A low p-value is rejection of the null. Jarque-Bera is the actual p-value of the Jarque-Bera normality test on the residuals. A low p-value is rejection of the null. 


\subsection{Regressions of the Log Returns of the US Dollar over the Log Returns of Gold, Oil, and US Stocks}

As prior evidence on the impact of the three intrinsic returns on the log returns of the US dollar, the latter is regressed on the log returns of these three assets without adjustment for dollar fluctuations. The impacts of changes in the prices of gold, oil, and stocks are all negative and highly significant statistically, the t-statistics being respectively 5.025896, 3.220237, and 4.531307. However the estimated coefficients are rather small ranging between -0.021160 for gold and -0.070569 for stocks. The two break point testers choose September 2002 as a calendar break. Because of this a dummy variable is generated that takes the value 1 before September 2002 and zero afterwards. This dummy is included interactively with the other three asset returns. A test that the interactive variables for gold and oil have both and jointly zero coefficients fails to be rejected with an actual p-value of 0.5841 . Therefore these two variables can be omitted from the analysis. Doing just that, and keeping the interactive variable with US stocks, produces the regression in column 3 of Table 4 .

Table 4. Regressions on $\Delta[\log ($ dollar $)]$

\begin{tabular}{|c|c|c|}
\hline \multirow[t]{2}{*}{ Constant } & 0.001713 & 0.001513 \\
\hline & (2.920517) & $(2.662789)[2.864752]$ \\
\hline \multirow[t]{2}{*}{$\Delta[\log ($ gold $)]$} & -0.064720 & -0.054270 \\
\hline & $(5.025896)$ & $(4.301240)[4.834111]$ \\
\hline \multirow{2}{*}{$\Delta[\log ($ stocks $)]$} & -0.070569 & -0.150896 \\
\hline & $(4.531307)$ & (6.911163) [6.506699] \\
\hline \multirow{2}{*}{$\Delta[\log ($ oil $)]$} & -0.021160 & -0.014803 \\
\hline & $(3.220237)$ & $(2.286361)[2.136827]$ \\
\hline \multirow{2}{*}{$\Delta[\log (\operatorname{dollar}(-1))]$} & 0.328469 & 0.290433 \\
\hline & (7.132098) & $(6.433072)[7.1513304]$ \\
\hline \multirow{2}{*}{$\mathrm{DUM}^{*} \Delta[\log ($ stocks $)]$} & & 0.159095 \\
\hline & & (5.079799) [4.522085] \\
\hline Adjusted R-Square & 0.272594 & 0.320225 \\
\hline Akaike information criterion & -6.203510 & -6.268491 \\
\hline Durbin-Watson statistic & 1.979003 & 2.002758 \\
\hline $\mathrm{Q}(6)$ & & 0.278 \\
\hline $\mathrm{Q}(12)$ & & 0.311 \\
\hline $\mathrm{Q}(18)$ & & 0.204 \\
\hline $\mathrm{Q}(24)$ & & 0.301 \\
\hline$Q^{2}(6)$ & & 0.152 \\
\hline $\mathrm{Q}^{2}(12)$ & & 0.312 \\
\hline $\mathrm{Q}^{2}(18)$ & & 0.408 \\
\hline $\mathrm{Q}^{2}(24)$ & & 0.549 \\
\hline $\begin{array}{l}\text { Quandt-Andrews unknown } \\
\text { breakpoint test }\end{array}$ & September 2002 & \\
\hline Bai-Perron break tests & September 2002 & \\
\hline Jarque-Bera & & 0.017993 \\
\hline ARCH test for 12 lags & & 0.3217 \\
\hline RESET test & & 0.6685 \\
\hline
\end{tabular}

Notes: In parentheses are absolute t-statistics. In brackets are t-statistics calculated with robust standard errors and covariance, or heteroscedasticity and autocorrelation consistent (HAC) standard errors, based upon Newey and West (1987). DUM is a dummy variable that takes a value of one up until August 2002, and zero thereafter. The Akaike information criterion for the regression that includes all three interactive variables with the dummy variable is -6.260408 , which is more than the one reported in column 3 with the restricted regression. In parentheses are absolute t-statistics. Q(k) is the actual p-value of the Ljung-Box Q-statistic for lag length $\mathrm{k}$ on the residuals. $\mathrm{Q}(\mathrm{k})$ 
tests for serial correlation. The null is for no serial correlation. A low p-value is rejection of the null. $\mathrm{Q}^{2}(\mathrm{k})$ is the actual p-value of the Ljung-Box Q-statistic for lag length $\mathrm{k}$ on the residuals squared. The null is for homoscedasticity or constant variance. A low p-value is rejection of the null. Jarque-Bera is the actual p-value of the Jarque-Bera normality test on the residuals. A low p-value is rejection of the null. The ARCH(12) test is the actual p-value of a heteroscedasticity test for ARCH effects up to the twelfth lag. The null is homoscedasticity or constant variance. A high p-value denotes homoscedasticity. The RESET test is due to Ramsey (1969). It includes in the regression the square and the cube of the fitted values. The actual p-value is reported. The null is for insignificance of these two variables, and a high p-value denotes good specification. The Quandt-Andrews unknown breakpoint test is due to Andrews (1993) and Andrews and Ploberger (1994). The number of breaks compared is 252 breaks. The Bai-Perron sequentially determined break identification is based on Bai and Perron (2003).

The coefficients on the returns of the three assets are still negative and highly significant statistically. Only the coefficient on the interactive variable with US stocks is positive and statistically significant, and carries the value 0.159095 . The coefficient on the log returns of US stocks is -0.150896 . A test whether these two coefficients are equal in absolute values produces an actual p-value of 0.7044 , failing to reject equality. This means that the depreciation of the US dollar leads to higher stock returns post 2002 but that the US dollar is not affected by US stocks before 2002. The econometric diagnostics on this unrestricted regression are all favorable. The regression does not suffer from serial correlation of residuals and conditional heteroscedasticity of these residuals. Unfortunately these residuals are still non-normal. As expected the Akaike information criterion is lower for this unrestricted regression.

Table 5. Regressions on $\Delta[\log ($ dollar $)]$

\begin{tabular}{|c|c|c|}
\hline Constant & $0.000718(1.121095)[1.044782]$ & $0.000860(1.382820)$ [1.575029] \\
\hline$\Delta[\log ($ gold $)]+\Delta[\log ($ dollar $)]$ & $-0.002400(0.166526)[0.127412]$ & \\
\hline$\Delta[\log ($ stocks $)]+\Delta[\log ($ dollar $)]$ & $0.027486(1.592795)[0.884136]$ & \\
\hline$\Delta[\log ($ oil $)]+\Delta[\log ($ dollar $)]$ & $-0.011022(1.534322)$ [1.344299] & \\
\hline$\Delta(\log [\operatorname{dollar}(-1))]$ & $0.370146(7.480724)[9.573063]$ & $0.383250(7.851833)[10.55948]$ \\
\hline Adjusted R-Square & 0.149814 & 0.144873 \\
\hline Akaike information criterion & -6.047540 & -6.050019 \\
\hline Durbin-Watson statistic & 1.922810 & 1.913963 \\
\hline $\mathrm{Q}(6)$ & 0.095 & 0.118 \\
\hline $\mathrm{Q}(12)$ & 0.265 & 0.264 \\
\hline $\mathrm{Q}(18)$ & 0.187 & 0.189 \\
\hline $\mathrm{Q}(24)$ & 0.148 & 0.183 \\
\hline$Q^{2}(6)$ & 0.032 & 0.122 \\
\hline $\mathrm{Q}^{2}(12)$ & 0.241 & 0.454 \\
\hline $\mathrm{Q}^{2}(18)$ & 0.610 & 0.797 \\
\hline $\mathrm{Q}^{2}(24)$ & 0.483 & 0.666 \\
\hline Jarque-Bera & 0.000000 & 0.000002 \\
\hline RESET test & 0.8115 & 0.4634 \\
\hline $\mathrm{ARCH}$ test for $12 \mathrm{lag}$ & 0.3111 & 0.4540 \\
\hline $\begin{array}{l}\text { Quandt-Andrews unknown } \\
\text { breakpoint test }\end{array}$ & September 2002 & No break \\
\hline Bai-Perron break tests & September 2002 & No break \\
\hline
\end{tabular}

Notes: In parentheses are absolute t-statistics. In brackets are t-statistics calculated with robust standard errors and covariance, or heteroscedasticity and autocorrelation consistent (HAC) standard errors, based upon Newey and West 
(1987). Q(k) is the actual p-value of the Ljung-Box Q-statistic for lag length $\mathrm{k}$ on the residuals. $\mathrm{Q}(\mathrm{k})$ tests for serial correlation. The null is for no serial correlation. A low p-value is rejection of the null. $\mathrm{Q}^{2}(\mathrm{k})$ is the actual $\mathrm{p}$-value of the Ljung-Box Q-statistic for lag length $\mathrm{k}$ on the residuals squared. The null is for homoscedasticity or constant variance. A low p-value is rejection of the null. Jarque-Bera is the actual p-value of the Jarque-Bera normality test on the residuals. A low p-value is rejection of the null. The $\mathrm{ARCH}(12)$ test is the actual p-value of a heteroscedasticity test for ARCH effects up to the twelfth lag. The null is homoscedasticity or constant variance. A high p-value denotes homoscedasticity. The RESET test is due to Ramsey (1969). It includes in the regression the square and the cube of the fitted values. The actual p-value is reported. The null is for insignificance of these two variables, and a high p-value denotes good specification. The Quandt-Andrews unknown breakpoint test is due to Andrews (1993) and Andrews and Ploberger (1994). The number of breaks compared is 252 breaks. The Bai-Perron sequentially determined break identification is based on Bai and Perron (2003).

\subsection{Regressions of the Log Returns of the US Dollar over the Intrinsic Log Returns of Gold, Oil, and US Stocks}

Having established the law of one price for gold, oil, and stocks, the intrinsic returns on these three assets can be calculated. These are nothing else but the actual log returns plus the log returns of the US dollar. They measure the returns on the three assets if the US dollar rate is taken as invariable or flat. Table 5 provides for a regression of log returns of the US dollar on the intrinsic returns of the three assets. Ordinary and robust standard errors are computed. The null hypothesis that the coefficients on the three asset intrinsic returns are jointly zero fails to be rejected with an actual p-value of 0.1440. It is concluded that the US dollar is independent of the fluctuations of the intrinsic returns of these three assets. Although this implies that the US dollar cannot be predicted by variations in gold, oil, and US stocks, it also implies that Markowitz diversification is worthwhile, especially for foreigners. The unrestricted regression that includes all three intrinsic log returns doe not suffer from first-order or higher-order serial correlation of the residuals, the Durbin-Watson statistic being 1.9222810, and the actual p-values of the Ljung-Box Q-statistics being all over $5 \%$. Moreover the RESET test rejects misspecification. The ARCH test, for 12 lags, rejects heteroscedasticity. One peculiar result is that the Quandt-Andrews unknown breakpoint test selects the same calendar break as before on September 2002 with an actual p-value less than 0.0001 . Therefore this necessitates exploring the effect of the break on the regression. Before that, let it be mentioned that the restricted regression, without the intrinsic log returns of the three assets, has well-behaved residuals, and that the Akaike information criterion is lower than the one on the unrestricted regression, implying that the restricted regression is better than the unrestricted one. In addition this restricted regression is stable over time, no calendar breaks being selected.

2.6 Regressions of the Log Returns of the US Dollar over the Intrinsic Log Returns of Gold, Oil, and US Stocks with a Calendar Break

Table 6 gives the results of the estimation of regressions of the log returns of the US dollar over the three intrinsic log returns together with the respective three interactive variables with the dummy variable. The dummy is also included as a shift variable with the intercept. Although not all coefficients are statistically significant the Akaike information criterion selects the totally unrestricted regression (column 2 of Table 6) over the restricted versions (columns 3 and 4 of Table 6). In any case there are three coefficients that are separately statistically significant. The first is for the pre-2002 intrinsic gold return. This coefficient is positive implying that higher intrinsic gold returns are associated with an appreciation of the US dollar. The second and third coefficients are those on pre-2002 and post-2002 intrinsic returns of US stocks. The two coefficients are symmetric: +0.128588 for the period pre-2002, and -0.131741 for the period post-2002. This means that higher US stocks were associated with an appreciation of the US dollar pre-2002, and with a depreciation of the US dollar post-2002. In absolute values these two coefficients are insignificantly different. So their sum is zero with a t-statistic of -0.095957. A test that all the other 4 coefficients are jointly insignificant statistically produces an actual p-value of 0.1928 failing to reject the null of statistical insignificance. Not only is the unrestricted model preferred according to the Akaike information criterion but the RESET test also favors this unrestricted model. This test has a p-value of 0.0701 for the unrestricted version and a p-value of 0.0372 for the restricted. However, all other diagnostics are similar: absence of first-order and higher-order serial correlation of residuals, absence of ARCH effects, absence of conditional heteroscedasticity in residuals, and most importantly all residuals are normally distributed, a feature which is lacking in other specifications of the regressions.

\subsection{Average Log Returns and Average Intrinsic Log Returns in the Short Run and in the Long Run}

To calculate average returns the asset returns are regressed on a constant with the inclusion of the lagged dependent variable. The long run return is equal to this constant, or short run return, divided by one minus the coefficient on the lagged dependent variable. The average log returns of the US dollar and of oil are statistically insignificantly 
different from zero. This applies to the short run and to the long run. The average short run and long run intrinsic log returns of oil are also statistically insignificantly different from zero. As for gold the long run average of its $\log$ returns is statistically significant with robust standard errors but insignificant without robust standard errors. The short run gold average return is insignificant statistically. The intrinsic gold average return is an annualized $9.7416 \%$, which is surprising. As for the last two variables, i.e. the US stocks average returns, all are statistically significant, in the short run and in the long run, with adjustment to intrinsic values or without such an adjustment. The US stocks average annualized return ranges between $5.6928 \%$ in the short run and $8.0616 \%$. in the long run The intrinsic US stocks average annualized return ranges between $6.9132 \%$ in the short run and $9.7680 \%$ in the long run.

What is important for portfolio analysis is not only average returns but pair-wise correlation coefficients and individual standard deviations. In general the US dollar is weakly negatively correlated with the log returns of gold, oil, and US stocks. This is due undoubtedly to the law of one price. Intrinsic log returns of gold, oil, and US stocks are independent from the US dollar. In what concerns standard deviations, obtained by multiplying the monthly standard deviation by the square root of 12 , there are as follows: $4.3894 \%$ for the US dollar, $15.6020 \%$ for gold, $31.2330 \%$ for oil, and $12.7818 \%$ for US stocks. The annualized standard deviations of the intrinsic variables are $19.6034 \%$ for gold, $30.35043 \%$ for oil, and $12.7534 \%$ for US stocks. What is particularly remarkable is the high volatility of oil and its flat return. It is an avenue for future research to investigate whether oil is a sufficient diversifier in portfolios, or that its flat return and high volatility make it unworthy of consideration.

Table 6. Regressions on $\Delta[\log ($ dollar $)]$

\begin{tabular}{|c|c|c|c|}
\hline Constant & $\begin{array}{c}0.000113 \\
(0125773)[0.88671\end{array}$ & $\begin{array}{c}0.000285 \\
(0.484979)[0.510031]\end{array}$ & $\begin{array}{c}0.000285 \\
(0.484979)[0.510004]\end{array}$ \\
\hline DUM & $\begin{array}{c}(0.125773)[0.8867] \\
0.000541\end{array}$ & $(0.484979)[0.510031]$ & \\
\hline & $(0.453374)[0.479523]$ & & \\
\hline$\Delta[\log ($ gold $)]+\Delta[\log ($ dollar $)]$ & -0.024176 & & \\
\hline & $(-1.414105)[1.378988]$ & & \\
\hline \multirow{2}{*}{$\operatorname{DUM}\{\Delta[\log ($ gold $)]+\Delta[\log ($ dollar $)]\}$} & 0.072990 & 0.051111 & 0.051111 \\
\hline & $(2.724742)[3.151462]$ & (2.471658) [2.997136] & (2.471658) [2.996168] \\
\hline \multirow[t]{2}{*}{$\Delta[\log ($ stocks $)]+\Delta[\log ($ dollar $)]$} & -0.116557 & -0.131741 & \\
\hline & $(4.406567)[2.840948]$ & $(5.056558)[2.868243]$ & \\
\hline \multirow{2}{*}{$\operatorname{DUM}\{\Delta[\log ($ stocks $)]+\Delta[\log ($ dollar $)]\}$} & 0.245285 & 0.260330 & 0.128588 \\
\hline & $(7.263447)[5.235602]$ & $(7.847630)$ [5.279790] & (6.340208) [7.353356] \\
\hline \multirow[t]{2}{*}{$\Delta[\log ($ oil $)]+\Delta[\log ($ dollar $)]$} & -0.028259 & & \\
\hline & $(2.400516)[1.673646]$ & & \\
\hline \multirow[t]{2}{*}{$\operatorname{DUM}\{\Delta[\log ($ oil $)]+\Delta[\log ($ dollar $)]\}$} & 0.033501 & & \\
\hline & (2.353939) [1.775077] & & \\
\hline$(1-\mathrm{DUM})\{\Delta[\log ($ stocks $)]+$ & & & -0.131741 \\
\hline$\Delta[\log ($ dollar $)]\}$ & & & $(5.056558)[2.868189]$ \\
\hline \multirow[t]{2}{*}{$\Delta[\log (\operatorname{dollar}(-1))]$} & 0.275411 & 0.293672 & 0.293672 \\
\hline & $(5.828386)$ [7.150194] & $(6.363668)[8.056533]$ & (6.36668) [8.055304] \\
\hline Adjusted R-Square & 0.288603 & 0.277734 & 0.277734 \\
\hline Akaike information criterion & -6.214844 & -6.210602 & -6.210602 \\
\hline Durbin-Watson statistic & 1.929075 & 1.924129 & 1.924129 \\
\hline $\mathrm{Q}(6)$ & 0.194 & 0.378 & 0.378 \\
\hline $\mathrm{Q}(12)$ & 0.201 & 0.446 & 0.446 \\
\hline $\mathrm{Q}(18)$ & 0.327 & 0.566 & 0.566 \\
\hline $\mathrm{Q}(24)$ & 0.182 & $0, .311$ & 0.311 \\
\hline$Q^{2}(6)$ & 0.520 & 0.321 & 0.321 \\
\hline$Q^{2}(12)$ & 0.814 & 0.559 & 0.559 \\
\hline
\end{tabular}




\begin{tabular}{cccc}
\hline $\mathrm{Q}^{2}(18)$ & 0.649 & 0.435 & 0.435 \\
$\mathrm{Q}^{2}(24)$ & 0.636 & 0.414 & 0.414 \\
& & & \\
Jarque-Bera & 0.419579 & 0.621675 & 0.621675 \\
RESET test & 0.0701 & 0.0372 & 0.0372 \\
ARCH test for 12 lags & 0.6164 & 0.3349 & 0.3349 \\
Breusch-Godfrey serial correlation & & & \\
LM test with 12 lags & 0.1739 & 0.4324 & 0.4324 \\
\hline
\end{tabular}

Notes: DUM is a dummy variable that takes a value of one up until August 2002, and zero thereafter. In parentheses are absolute t-statistics. In brackets are t-statistics calculated with robust standard errors and covariance, or heteroscedasticity and autocorrelation consistent (HAC) standard errors, based upon Newey and West (1987). See notes under Table 4 for the $\mathrm{Q}(\mathrm{k}), \mathrm{Q}^{2}(\mathrm{k})$, Jarque-Bera, RESET, and ARCH tests.

Table 7. Estimates of monthly short run and long run compound returns

\begin{tabular}{|c|c|c|c|c|c|}
\hline Z & $\begin{array}{c}\text { Constant } \\
\text { and short run } \\
\text { return }\end{array}$ & $\begin{array}{l}\text { Coefficient } \\
\text { on } Z_{t-1}\end{array}$ & $\begin{array}{l}\text { Long run } \\
\text { return }\end{array}$ & $\begin{array}{l}\text { Adjusted } \\
\text { R-Square }\end{array}$ & $\begin{array}{c}\text { Durbin-Watson } \\
\text { statistic }\end{array}$ \\
\hline$\Delta[\log ($ dollar $)]$ & $\begin{array}{c}0.000860 \\
(1.382820) \\
{[1.575029]}\end{array}$ & $\begin{array}{c}0.383250 \\
(7.851833) \\
{[10.55948]}\end{array}$ & $\begin{array}{c}0.001395 \\
(1.391404) \\
{[1.543734]}\end{array}$ & 0.144873 & 1.913963 \\
\hline$\Delta[\log ($ gold $)]$ & $\begin{array}{c}0.004160 \\
(1.754848) \\
{[1.848468]}\end{array}$ & $\begin{array}{c}-0.117969 \\
(2.251768) \\
{[2.170979]}\end{array}$ & $\begin{array}{c}0.003721 \\
(1.760164) \\
{[2.825151]}\end{array}$ & 0.011242 & 2.018845 \\
\hline$\Delta[\log ($ stocks $)]$ & $\begin{array}{c}0.004744 \\
(2.505833) \\
{[2.286622]}\end{array}$ & $\begin{array}{c}0.293902 \\
(5.803711) \\
{[4.707682]}\end{array}$ & $\begin{array}{c}0.006718 \\
(2.544588) \\
{[2.607824]}\end{array}$ & 0.083656 & 1.930136 \\
\hline$\Delta[\log ($ oil $)]$ & $\begin{array}{c}0.002137 \\
(0.463379) \\
{[0.530689]}\end{array}$ & $\begin{array}{c}0.259341 \\
(5.055356) \\
{[2.913157]}\end{array}$ & $\begin{array}{c}0.002886 \\
(0.463681) \\
{[0.544436]}\end{array}$ & 0.064359 & 1.973055 \\
\hline$\Delta[\log ($ gold $)]+\Delta[\log ($ dollar $)]$ & $\begin{array}{c}0.008118 \\
(3.217118) \\
{[3.304465]}\end{array}$ & & & & 2.023973 \\
\hline$\Delta[\log ($ stocks $)]+\Delta[\log ($ dollar $)]$ & $\begin{array}{c}0.005761 \\
(3.582821) \\
{[3.447869]}\end{array}$ & $\begin{array}{c}0.292215 \\
(6.860699) \\
{[6.576562]}\end{array}$ & $\begin{array}{c}0.008140 \\
(3.660060) \\
{[3.644237]}\end{array}$ & 0.084365 & 1.974940 \\
\hline$\Delta[\log ($ oil $)]+\Delta[\log ($ dollar $)]$ & $\begin{array}{c}0.003253 \\
(0.720293) \\
{[0.821576]}\end{array}$ & $\begin{array}{c}0.233525 \\
(4.523816) \\
{[2.772099]}\end{array}$ & $\begin{array}{c}0.004244 \\
(0.721296) \\
{[0.853087]}\end{array}$ & 0.051704 & 1.971611 \\
\hline
\end{tabular}

Notes: Absolute t-statistics in parentheses. In brackets are t-statistics calculated with robust standard errors and covariance, or heteroscedasticity and autocorrelation consistent (HAC) standard errors, based upon Newey and West (1987). The long run return is equal to the constant, or short run return, divided by one minus the coefficient on $\mathrm{Z}_{\mathrm{t}-1}$.

\subsection{Some Limitations}

The paper has some limitations. First, it is not known whether the dollar should be the dependent or one of the independent variables. Second, the presence of a break seems to be certain. The problem lies in that the month of the break changes with the model, with the econometric specification, with the included variables, with the exchange rate used, and whether the dollar is a dependent variable or not. The future will reveal why these calendar breaks are so unstable and why there is a break in the first instance. The presence of a calendar break denotes that the relation is inherently non-linear, although the use of categorical variables may alleviate this problem. All these are avenues for future research.

\section{Conclusion}

The purpose of this paper is to study the relation of US stocks, gold, and oil with the trade-weighted US dollar foreign exchange rate. First the law of one price is evaluated. This law stipulates that there is an inverse relation between the US dollar and the other three assets. If the US dollar appreciates the other three assets should fall by the same absolute amount for the simple reason that these assets are denominated in US dollars and because nothing 
inherently new has occurred to warrant a change in their returns. It is found that the law of one price applies to US stocks, gold, and oil, not only in the short run but also in the long run. Next intrinsic returns are calculated. Intrinsic returns are defined as those asset returns that omit the change in the US dollar. Although raw returns are marginally and weakly negatively correlated with the US dollar, intrinsic returns and the US dollar are essentially independent. Whether the raw series or the intrinsic series are considered the data is subject to a calendar break in September 2002. Before this date raw and intrinsic returns of US stocks are positively correlated with the US dollar, while they are negatively correlated afterwards. As a final step average returns for all seven series are calculated for the short run and the long run. Notably the US dollar and oil have both average long run and short run returns that are insignificantly different from zero. The implications for portfolio analysis are clear-cut: investors should hold a portfolio that is long in equity, gold and oil. This is true because of the low pair-wise correlations. At best these correlations are statistically insignificantly different from zero, but could be slightly negative. It may seem that foreigners benefit additionally from a stronger dollar. However the US dollar has itself a zero average return.

\section{References}

Abhyankar, A., Xu, B., \& Wang, J. (2013). Oil price shocksand the stock market: evidence from Japan. The Energy Journal, 34(2), 199-222. http://dx.doi.org/10.5547/01956574.34.2.7

Akram, Q. F. (2009). Commodity prices, interest rates and the dollar. Energy Economics, 31(6), 838-851. http://dx.doi.org/10.1016/j.eneco.2009.05.016

Andrews, D. W. K. (1993). Tests for parameter instability and structural change with unknown change point. Econometrica, 61(4), 821-856. http://dx.doi.org/10.2307/2951764

Andrews, D. W. K., \& Ploberger, W. (1994). Optimal tests when a nuisance parameter is present only under the alternative. Econometrica, 62(6), 1383-1414. http://dx.doi.org/10.2307/2951753

Azar, S. A. (2013a). US stocks and the US dollar. International Journal of Financial Research, 4(4), 91-106. http://dx.doi.org/10.5430/ijfr.v4n4p91

Azar, S. A. (2013b). US stocks and the US dollar II. International Research Journal of Finance and Economics, 117, 188-216.

Azar, S. A. (2014). The US Dow and the US dollar. Applied Financial Economics Letters, 21(10), 683-686. http://dx.doi.org/10.1080/13504851.2014.884690

Bai, J., \& Perron, P. (2003). Computation and analysis of multiple structural change models. Journal of Applied Econometrics, 18(1), 1-22. http://dx.doi.org/10.1002/jae.659

Baur, D. G., \& Lucey, B. M. (2010). Is gold a hedge or a safe haven? Analysis of stocks, bonds and gold. The Financial Review, 45, 217-229. http://dx.doi.org/10.1111/j.1540-6288.2010.00244.x

Beckmann, J., \& Czudaj, R. (2013). Oil and gold price dynamics in a multivariate cointegration framework. International Economics and Economic Policy, 10, 453-468. http://dx.doi.org/10.1007/s10368-013-0237-8

Bollerslev, T., \& Wooldridge, J. M. (1992). Quasi-maximum likelihood estimation and inference in dynamic models with time varying covariances. Econometric Reviews, 11, 143-172. http://dx.doi.org/10.1080/07474939208800229

Bonitsis, T. H., \& Rezvani, F. (2010). Is there a U.S. dollar-petroleum price nexus? Proceedings of the Northeast Business \& Economic Association, 239-244.

Hammoudeh, S., Sari, R., \& Ewing, B. T. (2009). Relationships among strategic commodities and with financial variables: a new look. Contemporary Economic Policy, 27(2), 251-264. http://dx.doi.org/10.1111/j.1465-7287.2008.00126.x

Inci, A. C., \& Lee, B. S. (2011). Dynamic relations between stock returns and exchange rate changes. European Financial Management. http://dx.doi.org/10.1111/j.1468-036X.2011.00621.x

Ivanov, S. I. (2013). The influence of ETFs on the price discovery of gold, silver and oil. Journal of Economics and Finance, 37, 453-462. http://dx.doi.org/10.1007/s12197-011-9205-8

Kollias, C., Mylodinis, N., \& Paleologou, S. (2012). The nexus between exchange rates and stock markets: evidence from the euro-dollar rate and composite European stock indices using rolling analysis. Journal of Economics and Finance, 36, 136-147. http://dx.doi.org/10.1007/s12197-010-9129-8 
Lee, Y-H, Huang, Y-L, \& Yang, H-J. (2012). The asymmetric long-run relationship between crude oil and gold futures. Global Journal of Business Research, 6(1), 9-15.

Malliaris, A. G., \& Malliaris, M. (2013). Are oil, gold and the euro inter-related? Time series and neural network analysis. Review of Quantitative Finance and Accounting, 40, 1-14. http://dx.doi.org/10.1007/s11156-011-0265-9

Miyazaki, T., \& Hamori, S. (2013). Testing the causality between the gold return and stock market performance: evidence for 'gold investment in case of emergency'. Applied Financial Economics, 23, 27-40. http://dx.doi.org/10.1080/09603107.2012.699184

Newey, W. K., \& West, K. D. (1987). A Simple, positive semi-definite, heteroskedasticity and autocorrelation-consistent covariance matrix. Econometrica, 55, 703-708. http://dx.doi.org/10.2307/1913610

Pukthuanthong, K., \& Roll, R. (2011). Gold and the dollar (and the euro, pound, and yen). Journal of Banking and Finance, 35(8), 2070-2083. http://dx.doi.org/10.1016/j.jbankfin.2011.01.014

Ramsey, J. B. (1969). Tests for specification errors in classical linear least squares regression analysis. Journal of the Royal Statistical Association, 62(319), 819-841.

Working, H. (1960). Note on the Correlation of First Differences of Averages in a Random Chain. Econometrica, 28(4), 916-918. http://dx.doi.org/10.2307/1907574

Zagaglia, P., \& Marzo, M. (2013). Gold and the US dollar. Quantitative Finance, 13(4), 571-582. http://dx.doi.org/10.1080/14697688.2012.708431 